\title{
Experimental research on effectiveness of the magnetic fluid seals for rotary shafts working in water
}

\author{
Zbigniew Szydło, \\ AGH University of Science and Technology \\ Leszek Matuszewski, \\ Gdansk University of Technology
}

\begin{abstract}
This paper presents course of research on ferro-fluidal seals used in water. The tests were carried out for a hydrophobic magnetic fluid and specially selected profiles of sealing lips at various linear velocities in sealing unit. Though the tests were preliminary their results showed that the research on application of magnetic fluids to seals working in liquid environment should be continued. From the point of view of development of ring drives the most important advantage of ferro-fluidal seals is their smallest drag as compared with seals of other types.
\end{abstract}

Keywords: propulsion systems operating in water, magnetic fluids, tightness, seals

\section{INTRODUCTION}

Seals containing a magnetic fluid, known as Magnetic Fluid (MF) seals (or Ferro-Fluidic (FF) seals) in subject-matter literature, have taken firm place in seal engineering because of their simple structure, high reliability and operational effectiveness. They are used in many crucial mechanisms of machines working in gaseous environment at the pressure lower than $0.5 \mathrm{MPa}$, as well as in vacuum devices $[1,2]$.

However only a few publications can be found on application of MF seals to devices working in liquid environment. Difficulties associated with application of MF seals working in liquids are greater than in the case of their work in gaseous environment because of specific phenomena occurring at the interface of two liquids. Some of the problems which require to be experimentally tested separately, are discussed in [3].

Material and structural elaboration of MF seals capable of effective working in liquid environment could be of a great importance for many industrial branches where tightness of mechanisms being in permanent contact with liquid decides on correct operation of devices. It is also important for propulsion systems of floating units which are in permanent contact with water, hence limitation or elimination of leakage is essential for maintaining assumed operational parameters of the devices.

A research on seals with applied magnetic fluid, intended for operating in water was initiated by the Laboratory of Seals and Application of Magnetic Fluids, Department of Construction and Operation of Machines, Mining \& Metallurgy Academy in Cracow in cooperation with the Department of Ship Theory and Design, Gdańsk University of Technology. A long-term aim of the research is to elaborate MF seals which will be capable of effective working also in shipborne devices.

In the previous publications of these authors [4] some aspects of application of MF seals in liquid environment were discussed and results of preliminary experiments carried out to assess possibility of effective operation of the seals submerged in liquid, were presented.

The experimental research on the problem has been continued and in further experiments other geometrical and structural versions of the seals and other kinds of magnetic fluid were used. In this publication is presented a summary of the tests have been performed so far with the use of the laboratory stand adjusted for testing MF seals in water.

The tests are still of a preliminary character, however in the opinion of these authors their results show directions in which further research on application of magnetic fluids to seals working in liquid environment, should be developed.

\section{AIM AND SCOPE OF THE RESEARCH}

The research was aimed at possible determination of effective operation of a MF seal installed on a rotating shaft immersed in a chamber full of tap water under pressure depending on the shaft's rotational speed, geometry of gap with magnetic fluid and construction of sealing unit.

The basic criterion of operational effectiveness of the seal was to maintain tightness of the testing chamber for an assumed operation time of the unit.

For all the investigations in the testing chamber the tap water was used as working medium. 
For the tests two kinds of magnetic fluid and two sealing sleeves of different geometry were used at the following pressure values of the working medium :

$\Rightarrow 0.15 \mathrm{MPa}$ - for the sealing sleeve of $0.1 \mathrm{~mm}$ gap and 8 sealing lips,

$\Rightarrow 0.05 \mathrm{MPa}$ - for the sealing sleeve of $0.3 \mathrm{~mm}$ gap and 4 sealing lips.

The tests were carried out at various rotational shaft speeds within the range from $125 \mathrm{rpm}$ to $6800 \mathrm{rpm}$.

A part of the tests was performed with the use of an additional protecting set of sealing rings : one of circular crosssection (O-ring) and another one of rectangular cross- section, placed from the side of working medium, before the basic MF seal. The test was aimed at making clear to which extent such design solution is effective, that was important for elaboration of further research program.

\section{THE TEST STAND AND MEASUREMENT SYSTEM}

The construction and mode of operation of the test stand was described in detail in [4].

Here are described only the testing head's elements crucial from the point of view of the investigations in question, as well as the measurement system used in the tests.

In Fig. 1 is shown the drawing (half-cross-section and half -view) of the head for testing MF seals in liquid environment. The most important parts are shown in colours.

Compressed air is delivered through the channel (11) (in yellow) to the elastic recess (9), that makes pressure of the liquid (12) (in blue) which directly impacts the seal unit $(1,2$, $3,4)$, increasing.

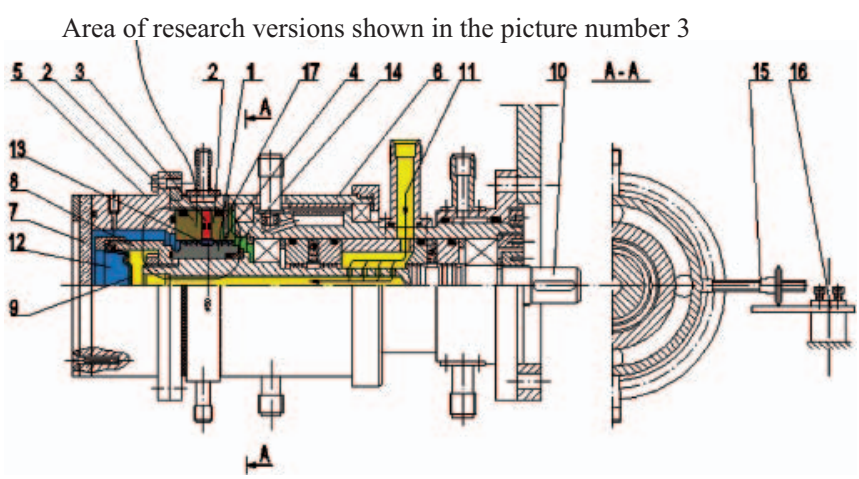

Fig. 1. Construction of the head for testing MF seals in liquid environment. Notation : $\mathbf{1}$-multi-lip sleeve, $\mathbf{2}$-pole shoes, $\mathbf{3}$-permanent magnets,

4 - magnetic fluid, 5 - testing head's casing, 6 - pivotable casing of head's bearings, 7 -transparent cover of testing head, $\mathbf{8}$-rubber membrane holder, 9 - rubber membrane, 10 - rotating shaft, 11 - compressed air channel, 12 -zone of pressure set in liquid-filled chamber, 13 -zone of liquid penetration to the chamber, 14-zone of liquid outflow due to leakage, 15 - pressing arm of torque-meter, 16 - extensometric beam for torque measuring, 17 - opening of magnetic fluid temperature indicator.

In Fig. 2 the schematic diagram of the control-measurement system and overall view of the test stand is presented.

To produce pressure in the water-filled chamber, was used the compressed air delivered from the tank (17) fed by the air compressor (16), to the inlet socket (10). Compressed air pressure and rate of flow are controlled by the pressure reducing valve (18) and the throttle valve (19). Air pressure at the inlet socket (10) is measured by the MBS 32 Danfoss pressure transducer (21) of the measurement range of $0 \ldots 1 \mathrm{MPa}$, as well as the indicating manometer of the measurement range up to $0.16 \mathrm{MPa}$. The cut-off valve (20) serves to close the compressed air channel when the set pressure is reached.

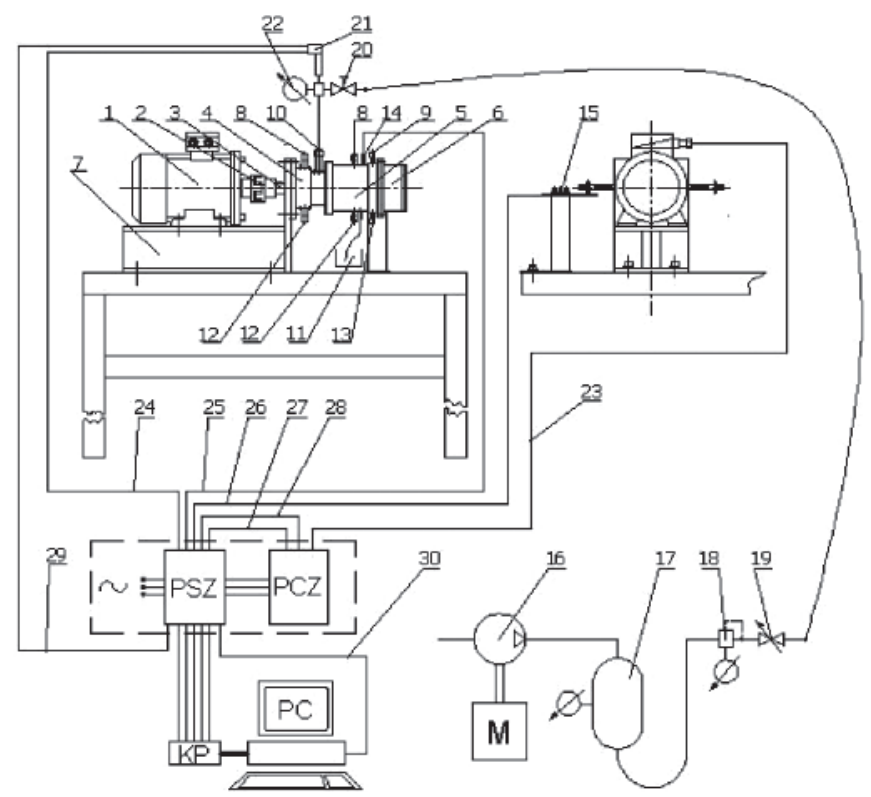

Fig. 2. Overall view and schematic diagram of the control-measurement system of the stand for testing MF seals. Notation : 1 -driving motor, $\mathbf{2}$-clutch, $\mathbf{3}$ - rotating shaft, $\mathbf{4}$ - casing of shaft bearings, $\mathbf{5}$ - pivotable casing of head's bearings, $\mathbf{6}$ - testing head's casing, 7 - testing stand's basement, $\mathbf{8}$-inlet sockets of cooling system of shaft seals, $\mathbf{9}$-inlet socket for cooling medium of the tested MF seal, 10 - compressed air supply socket, 11 -tank for leaks from the testing head, 12 - outlet sockets of cooling system of shaft seals, 13 - outlet socket for cooling medium of the tested MF seal, 14 - temperature gauge, 15 - extensometric beam for torque measuring, 16 - air compressor, 17 - compressed air tank, 18 - reducing valve, 19 - flow control valve, 20 -cut-off valve, 21 - pressure transducer, 22 - manometer, 23 - electric supply for driving motor, 24, 25, 26, 27, 28 -measuring lines for pressure, temperature, torque, rotational speed and power, 29, 30 -electric supply of pressure transducer and computer measurement system, PSZ - control-supply panel, $\boldsymbol{P C Z}$ - frequency converter, $\mathbf{K P}-$ measurement chart.

The testing stand is fitted with Pt 100 temperature gauge (14) for measuring magnetic fluid temperature in the seal, and the extensometric beam (15) for measuring the seal's anti-torque.

Rotational speed of the driving motor (1) is controlled by means of the frequency converter PCZ which makes it possible to measure rotational speed of the driving shaft and power absorbed by the driving motor.

Signals of pressure, temperature, torque, rotational speed and absorbed power are conducted through the measuring lines 24, 25, 26, 27 and 28 to the control- supply panel PSZ, and next to the five-channel measuring chart KP, of PCIA-71B type, cooperating with the PC by means of the ADVANTECH GENIE software of 2.12 version.

\section{MAGNETIC MATERIALS USED IN THE RESEARCH}

In the previously conducted tests [4] dealing with the seal of version A (Fig. 2) the C2- 40M magnetic fluid produced in Russia, was used.

In the research on the seals of B and C version the BM-30 magnetic fluid, also of Russian origin, was applied.

In Tab. 1 the basic properties of the fluids are presented.

Magnetic field in the sealing system was generated by means of the set of permanent magnet discs. In the tests of the seal of A version (Fig. 2) samarium - cobalt (Sm-Co) alloy magnets were used, and to that of version $\mathrm{B}$ and $\mathrm{C}$ - neodymium $(\mathrm{Nd})$ magnets.

Tab. 2 presents full characteristics of the permanent magnets used in the tests. 
Tab.1. Characteristics of magnetic fluids used in the research on MF seals working in water.

\begin{tabular}{|c|c|c|}
\hline Kind of fluid & C2-40M & BM-30 \\
\hline Basic fluid & Silicon fluid & Mineral oil \\
\hline Magnetic particles & $\begin{array}{c}\text { Magnetite : } \\
\mathrm{Fe}_{3} \mathrm{O}_{4}\end{array}$ & $\begin{array}{c}\text { Magnetite: } \\
\mathrm{Fe}_{3} \mathrm{O}_{4}\end{array}$ \\
\hline Density $\rho[\mathrm{g} / \mathrm{ml}]$ & 1.414 & 1.345 \\
\hline $\begin{array}{c}\text { Magnetization saturation } \\
\mathrm{M}_{\mathrm{s}}[\mathrm{kA} / \mathrm{m}]\end{array}$ & 39.1 & 37.5 \\
\hline $\begin{array}{c}\text { Plastic viscosity at } 20^{\circ} \mathrm{C}, \\
\eta_{\mathrm{pl}}[\mathrm{Pa} \mathrm{s}]\end{array}$ & 0.520 & 0.386 \\
\hline
\end{tabular}

Tab. 2. Basic properties and dimensions of the magnets used for the tests of MF seals in liquid environment

\begin{tabular}{|c|c|c|}
\hline Magnetic material & Sm-Co alloy & $\begin{array}{c}\text { Neodymium } \\
\mathbf{N 3 8}\end{array}$ \\
\hline $\begin{array}{c}\text { Residual magnetic } \\
\text { inductance } \mathrm{B}_{\mathrm{r}}[\mathrm{T}]\end{array}$ & 0.77 & 1.23 \\
\hline Coercive force $\mathrm{H}_{\mathrm{c}}[\mathrm{kA} / \mathrm{m}]$ & 540 & 912 \\
\hline $\begin{array}{c}\text { Maximum energy density } \\
(\mathrm{BH})_{\max }\left[\mathrm{kJ} / \mathrm{m}^{3}\right]\end{array}$ & 55 & 294 \\
\hline $\begin{array}{c}\text { Maximum working } \\
\text { temperature }\left[{ }^{\circ} \mathrm{C}\right]\end{array}$ & 250 & 150 \\
\hline $\begin{array}{c}\text { Dimensions of a single } \\
\text { magnet }[\mathrm{mm}]\end{array}$ & $\Phi 16 \times 5$ & $\Phi 15 \times 5$ \\
\hline \multicolumn{2}{|c}{} \\
\hline
\end{tabular}

The remaining elements of the magnetic core, i.e. pole shoes and sleeves fitted with sealing lips, were made of a low-carbon steel of good magnetic properties.

\section{DESIGN, GEOMETRICAL AND TESTING PARAMETERS OF THE SEALS}

In Fig. 3 are shown details of geometry and design solutions applied to various versions of the tested seals.

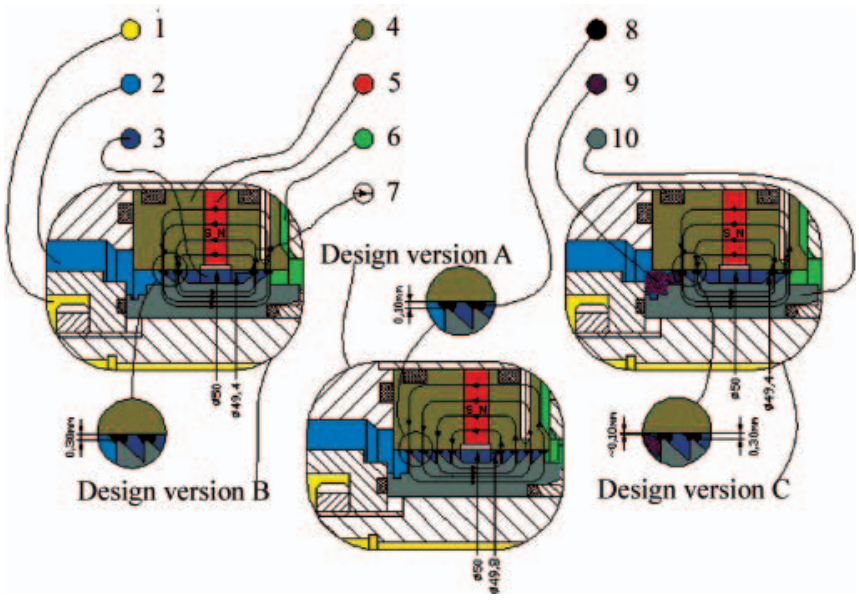

Fig. 3. Geometry of sealing lips and construction of seals in various design versions used in the tests. Versions $A$ and $B-$ without protecting rings, version $C$-fitted with the set of rings protecting $M F$ seal against direct influence of whole amount of water contained in the test chamber.

Notation : 1 -zone of compressed air, 2 -zone of water under pressure,

3 - zone of water penetration, 4 - pole shoes, 5 - set of permanent magnets,

$\mathbf{6}$ - zone of leakage, 7 -lines of magnetic force field, $\boldsymbol{8}$ - magnetic fluid, 9 - set of rings protecting MF sealing lips, 10 -multi-lip sleeve.
For all the tests was used the same set of the pole shoes of $50 \mathrm{~mm}$ - diameter sealing hole, having the set of permanent magnets inserted between them. In the version A twelve SmCo magnets of $\Phi 16 \mathrm{~mm} \times 5 \mathrm{~mm}$ in size, and in the versions $B$ and C twelve Nd magnets of $\Phi 15 \mathrm{~mm} \times 5 \mathrm{~mm}$, were used (Tab. 2).

In the version A the multi-lip sleeve of $49.8 \mathrm{~mm}$ outer diameter and eight sealing lips filled with magnetic fluid, was used. Value of the height of the gap filled with magnetic fluid amounted to $0,1 \mathrm{~mm}$. Such testing system was the subject of the preceding research described in [4].

In design versions $B$ and $C$ the multi-lip sleeve of $49.4 \mathrm{~mm}$ diameter and four sealing lips filled with magnetic fluid, was used. Value of the height of the gap filled with magnetic fluid amounted to $0.3 \mathrm{~mm}$. The choice of the number of sealing lips smaller than in the above mentioned tests resulted from the assumed lower value of liquid pressure in the chamber to be sealed, whereas the greater height of the gap with magnetic fluid made operation of the seal in a non-coaxial position of the shaft against the sleeve with pole shoes, possible.

Moreover, in the design version $\mathrm{C}$ the set of rings protecting MF seal against direct influence of the whole amount of water contained in the test chamber, was installed from the side of water under pressure, before the first sealing lip. The protecting set was composed of two rubber rings placed in series : one of circular and other of rectangular cross-section. Dimensions of the rings were so selected as to obtain the gap between the outer diameter of the rings and the inner diameter of the pole shoe equal to about $0.10 \mathrm{~mm}$ (see relevant detail for the design version C, Fig. 3). Tests of such design solution was aimed at checking the influence of limitation of magnetic fluid contact with the water contained in the chamber on ultimate rotational speed for the seal in question.

In Tab. 3 geometrical parameters of the tested seals are given.

Tab. 3. Geometrical parameters of the tested seals.

\begin{tabular}{|c|c|c|c|}
\hline Design version & A & B & C \\
\hline Outer diameter of pole shoes [mm] & 50 & 50 & 50 \\
\hline Number of sealing lips & 8 & 4 & 4 \\
\hline Inner diameter of sealing lips [mm] & 49.8 & 49.2 & 49.2 \\
\hline $\begin{array}{c}\text { Height of the gap filled } \\
\text { with magnetic fluid [mm] }\end{array}$ & 0.1 & 0.3 & 0.3 \\
\hline $\begin{array}{c}\text { Outer diameter } \\
\text { of protecting rings [mm] }\end{array}$ & lack & lack & 49.8 \\
\hline
\end{tabular}

In the tests of the seals of A version the C2-40M magnetic fluid was used (Tab. 1).

Eight-hour lasting series of the tests were carried out for the following rotational speeds : $125 ; 250 ; 500 ; 750 ; 1,000$; $1500 ; 2000 ; 3000 \mathrm{rpm}$. And, the test was performed of gradual continuous increasing the rotational speed up to the loss of tightness by the sealing unit. All the tests were carried out at the initial water pressure $\mathrm{p}=0.15 \mathrm{MPa}$ [4].

In the tests of the seals of $\mathrm{B}$ and $\mathrm{C}$ versions the BM-30 magnetic fluid was used (Tab. 1). For these seal versions was carried out one long test (lasting for over $200 \mathrm{~h}$ ) of the sleeve (B version) at constant speed of $3000 \mathrm{rpm}$, as well as several tests of the sleeve at various rotational speeds within the range from $3000 \mathrm{rpm}$ up to $6000 \mathrm{rpm}$ and for different duration time from a few minutes up to a few dozen hours. For the tests of $\mathrm{B}$ and $\mathrm{C}$ versions of the seal the initial water pressure of 0.05 $\mathrm{MPa}$ was set. 


\section{RUN AND RESULTS OF THE TESTS}

The way of preparation of the seals to testing, generation of water pressure in the chamber as well as starting and stopping procedures of the test stand are described in [4]. In the tests concerning A version of the seal the test's duration time and water pressure in the chamber was measured and amount of water leaking from the seal was monitored.

The procedures used in the tests of the seals of B and $\mathrm{C}$ versions were similar to those applied to the tests of the seals of A version. Also, the above mentioned measurements and observations were carried out, and in majority of the tests also the seal's anti-torque and temperature was measured. During the tests the measured quantities were read and recorded by the computer.

The test results of the particular seal versions are collected in Tab. 4, 5 and 6, for A, B and C seal versions, separately. In the tables are given basic operational parameters of the tests and values of anti-torque and temperature of the seal recorded during the tests. Results of the test run monitoring which concerned leakage quantity and changeability are also attached.

In the diagrams (Fig. 4 and 5) is presented comparison of changes of anti-torque and temperature of the seals of B and $\mathrm{C}$ versions operating in similar conditions during $2 \mathrm{~h}$ period.

In Tab. 4 are given parameters of the tests of seal of A version as well as results of the tests in the form of either occurrence of leakage or lack of it. The tests were aimed at checking correctness of the design concept of the test head and preliminary testing the MF seal's operation in water. The seal operated correctly during several-hour tests at various rotational speeds. Lack of its tightness appeared in the last test at the rotational speed of $6800 \mathrm{rpm}$ (the circumferential speed of $17.80 \mathrm{~m} / \mathrm{s}$ ).

In Tab. 5 parameters of the tests of the seal of B version are given. In the tests the sleeve fitted with four sealing lips and of $0.3 \mathrm{~mm}$ gap height was applied. The cycle of tests was aimed at checking the operational effectiveness of the seal during a longer time period at the rotational speed of $3000 \mathrm{rpm}$ commonly used in industrial practice, as well as at determining the rotational speed range leading to loss of tightness.

In the tests was used the BM-30 magnetic fluid based on mineral oil (Tab.1), other than that previously applied.
Tab. 4. Parameters and results of the tests of the MF seal of $A$ version. Magnetic fluid : C2-40M (Tab.1). Number of sealing lips

8. Height of the gap filled with magnetic fluid: $0.10 \mathrm{~mm}$. Water pressure in the test chamber : $0.15 \mathrm{MPa}$.

\begin{tabular}{|c|c|c|c|c|}
\hline $\begin{array}{l}\text { No. } \\
\text { of } \\
\text { test }\end{array}$ & $\begin{array}{c}\text { Rotational } \\
\text { speed } \\
\text { [rpm] }\end{array}$ & $\begin{array}{c}\text { Circum- } \\
\text { ferential } \\
\text { speed } \\
{[\mathrm{m} / \mathrm{s}]} \\
\end{array}$ & $\begin{array}{c}\text { Duration } \\
\text { time } \\
{[\mathrm{h}]}\end{array}$ & $\begin{array}{c}\text { Comments / } \\
\text { Leakage }\end{array}$ \\
\hline A1 & 125 & 0.33 & 8.0 & $\begin{array}{c}\text { Replacement } \\
\text { of MF / No } \\
\text { leakage }\end{array}$ \\
\hline A2 & 250 & 0.65 & 8.0 & $\begin{array}{c}\text { No replacement } \\
\text { of } \mathrm{MF} / \mathrm{No} \\
\text { leakage }\end{array}$ \\
\hline A3 & 500 & 1.31 & 8.0 & $\begin{array}{c}\text { No replacement } \\
\text { of } \mathrm{MF} / \mathrm{No} \\
\text { leakage }\end{array}$ \\
\hline A4 & 750 & 1.96 & 8.0 & $\begin{array}{c}\text { No replacement } \\
\text { of } \mathrm{MF} / \mathrm{No} \\
\text { leakage }\end{array}$ \\
\hline A5 & 1000 & 2.62 & 8.0 & $\begin{array}{c}\text { No replacement } \\
\text { of } \mathrm{MF} / \mathrm{No} \\
\text { leakage }\end{array}$ \\
\hline A6 & 1500 & 3.93 & 8.0 & $\begin{array}{c}\text { No replacement } \\
\text { of } \mathrm{MF} / \mathrm{No} \\
\text { leakage }\end{array}$ \\
\hline A7 & 2000 & 5.24 & 8.0 & $\begin{array}{c}\text { No replacement } \\
\text { of } \mathrm{MF} / \mathrm{No} \\
\text { leakage }\end{array}$ \\
\hline A8 & 3000 & 7.85 & 8.0 & $\begin{array}{c}\text { No replacement } \\
\text { of } \mathrm{MF} / \mathrm{No} \\
\text { leakage }\end{array}$ \\
\hline A9 & $\begin{array}{l}\text { Uniformly } \\
\text { increasing } \\
\text { from } 0 \text { up } \\
\text { to } 6800\end{array}$ & $\begin{array}{c}\text { Uniformly } \\
\text { increasing } \\
\text { from } 0 \text { up to } \\
17.80\end{array}$ & 0.30 & $\begin{array}{c}\text { No replacement } \\
\text { of MF / Sudden } \\
\text { leakage at } 6800 \\
\text { rpm }\end{array}$ \\
\hline
\end{tabular}

Tab. 5. Parameters and results of the tests of the MF seal of B version. Magnetic fluid : BM-30 (Tab.1). Number of sealing lips : 4. Height of the gap filled with magnetic fluid: $0.30 \mathrm{~mm}$. Water pressure in the test chamber : $0.05 \mathrm{MPa}$.

\begin{tabular}{|c|c|c|c|c|c|c|c|c|}
\hline \multirow{2}{*}{$\begin{array}{c}\text { No. of } \\
\text { test }\end{array}$} & \multirow{2}{*}{$\begin{array}{l}\text { Rotational } \\
\text { speed, } \\
\text { [rpm] }\end{array}$} & \multirow{2}{*}{$\begin{array}{l}\text { Circumferential } \\
\text { speed, } \\
{[\mathrm{m} / \mathrm{s}]}\end{array}$} & \multirow{2}{*}{$\begin{array}{l}\text { Testing } \\
\text { time, } \\
\text { [h] }\end{array}$} & \multicolumn{2}{|c|}{$\begin{array}{l}\text { Anti-torque, } \\
{[\mathrm{Nm}]}\end{array}$} & \multicolumn{2}{|c|}{$\begin{array}{c}\text { Temper. } \\
{\left[{ }^{\circ} \mathrm{C}\right]}\end{array}$} & \multirow{2}{*}{ Comments/ Leakage } \\
\hline & & & & Initial & Final & Initial & Final & \\
\hline B1 & 3000 & 7.85 & 201 & \multicolumn{2}{|c|}{ Not measured } & \multicolumn{2}{|c|}{ Not measured } & Replacement of MF / No leakage \\
\hline $\mathrm{B} 2$ & 4000 & 10.47 & 1.5 & \multicolumn{2}{|c|}{ Not measured } & \multicolumn{2}{|c|}{ Not measured } & $\begin{array}{l}\text { No replacement of MF / After } 62 \mathrm{~min} \text {. } \\
\text { of tests - a leakage increasing } \\
\text { from } 2 \text { drops per minute to continuous flow }\end{array}$ \\
\hline B3 & 4000 & 10.47 & 0.25 & \multicolumn{2}{|c|}{ Not measured } & \multicolumn{2}{|c|}{ Not measured } & $\begin{array}{c}\text { Replacement of MF / After } 2 \text { min. } \\
\text { of test - permanent leakage } \\
\text { from } 2 \text { to } 4 \text { drops per minute }\end{array}$ \\
\hline B4 & 3000 & 7.85 & 66 & 0.130 & 0.090 & 21 & 52 & No replacement of MF / No leakage \\
\hline \multirow{3}{*}{ B5 } & 3500 & 9.16 & 0.10 & \multirow{3}{*}{\multicolumn{2}{|c|}{$\begin{array}{l}\text { Changing } \\
\text { within the } \\
\text { range from } \\
0.140 \text { to } 0.06\end{array}$}} & \multirow{3}{*}{22} & \multirow{3}{*}{56} & $\begin{array}{l}\text { No replacement of MF / After } 1 \mathrm{~min} \\
\text { of test - permanent leakage } \\
\text { from } 1 \text { to } 2 \text { drops per minute }\end{array}$ \\
\hline & 3000 & 7.85 & 5.00 & & & & & Decrease of rotational speed - no leakage \\
\hline & 4000 & 10.47 & 0.25 & & & & & $\begin{array}{c}\text { Increase of rotational speed - a leakage } \\
\text { of about } 8 \text { drops per minute }\end{array}$ \\
\hline
\end{tabular}


In the test carried out at the constant rotational speed of $3000 \mathrm{rpm}$ for $201 \mathrm{~h}$ period (the test B1) no leaks were observed. They appeared in the tests B2 and B3 carried out at the rotational speed of $4000 \mathrm{rpm}$. In the test B2 carried out without replacement of the magnetic fluid used in the preceding test, extensive leakage occurred after one - hour operation, whereas in the case of the test B3 performed with the use of the replaced magnetic fluid a permanent but small leakage occurred just after starting the test, hence it was terminated after about 15 minutes of the seal's operation.

Interesting, that in the test $\mathrm{B} 4$ performed at the rotational speed of $3000 \mathrm{rpm}$ without any replacement of the magnetic fluid used in the preceding test no leakage was observed for all the testing period of $66 \mathrm{~h}$. After about $2 \mathrm{~h}$ the anti-torque value reached about $0,09 \mathrm{Nm}$, and the seal's temperature value - about $52^{\circ} \mathrm{C}$. The values maintained constant up to the termination of the test.

The test B5 was carried out at various rotational speeds changeable during the test. The first symptoms of leakage was observed at the rotational speed value of about $3500 \mathrm{rpm}$.

In Tab. 6 are presented parameters and results of the tests of $\mathrm{MF}$ seal of $\mathrm{C}$ version, in which the additional set of rings protecting the seal against direct influence of the whole amount of water contained in the test chamber (Fig. 3, seal version C).

In majority of the tests performed in the series a significant increase of temperature of magnetic fluid in the seal occurred. The temperature increase was often accompanied by the increase of anti-torque of the seal, similar to that observed during the tests $\mathrm{C} 1, \mathrm{C} 2, \mathrm{C} 5$ and $\mathrm{C} 6$. In the range of the rotational speeds up to $4800 \mathrm{rpm}(12.57 \mathrm{~m} / \mathrm{s})$ no leakage was observed. Attention should be paid to the relatively short duration time of the tests of the series, resulting from the increasing of the seal's temperature. In the test C6 performed at the rotational speed of $5400 \mathrm{rpm}$ a small leakage was observed, and it was very intensive in the test $\mathrm{C} 7$ carried out at the rotational speed of $6000 \mathrm{rpm}$.

Tab. 6. Parameters and results of the tests of the $M F$ seal of $C$ version fitted with an additional set of rings protecting the MF seal. Magnetic fluid: BM-30 (Tab.1). Number of sealing lips : 4. Height of the gap filled with magnetic fluid : $0.30 \mathrm{~mm}$. Height of the gap of protecting rings : $0.10 \mathrm{~mm}$. Water pressure in the test chamber: $0.05 \mathrm{MPa}$
In Fig. 4 are shown changes of seal anti-torque for two hours of testing the seals of B and $\mathrm{C}$ versions (Fig. 3) working in similar conditions. The anti-torque changes of $\mathrm{B}$ version of the seal are similar to those obtained during the tests of the seal in gaseous environment [5]. It can be observed that the anti-torque of the $\mathrm{C}$ version of the seal fitted with the additional protecting set of sealing rings is much greater than that of its $B$ version without the additional elements.

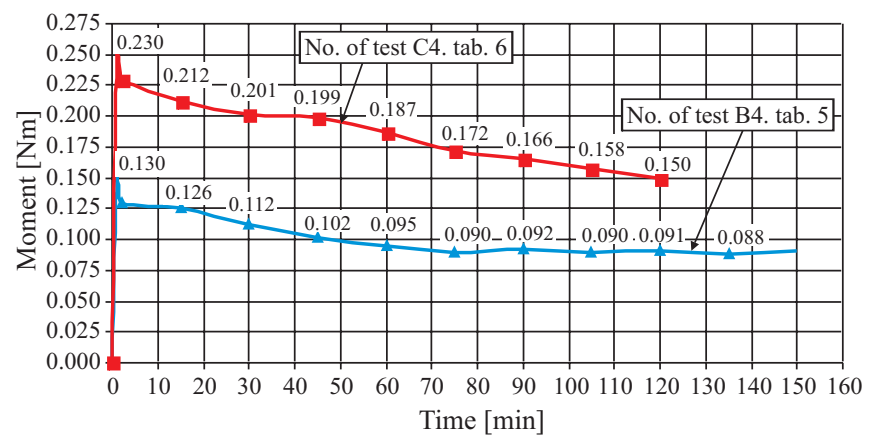

Fig. 4. Changes of anti-torque of the tested MF seals in B version - without protecting rings, and in $C$ version - with additional protecting rings, recorded during two hours of the test.

In Fig. 5 are shown changes of seal temperature during two hours of testing the seals of B and C versions (Fig. 3) working in similar conditions. It can be observed that temperature of

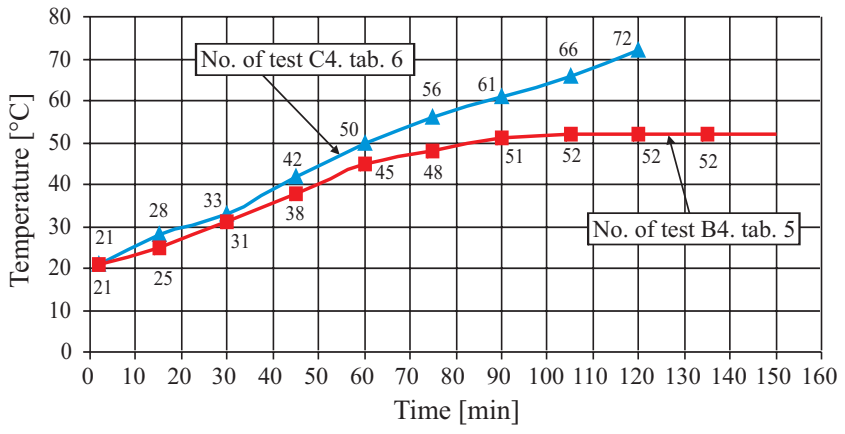

Fig. 5. Temperature changes of the tested MF seals of B version - without protecting rings, and of $C$ version - with additional protecting rings, recorded during two hours of the test.

\begin{tabular}{|c|c|c|c|c|c|c|c|c|}
\hline \multirow{2}{*}{$\begin{array}{c}\text { No. } \\
\text { of } \\
\text { test }\end{array}$} & \multirow{2}{*}{$\begin{array}{c}\text { Rotational } \\
\text { speed. [rpm] }\end{array}$} & \multirow{2}{*}{$\begin{array}{c}\text { Circumferential } \\
\text { speed. } \\
{[\mathrm{m} / \mathrm{s}]} \\
\end{array}$} & \multirow{2}{*}{$\begin{array}{l}\text { Testing } \\
\text { time. [h] }\end{array}$} & \multicolumn{2}{|c|}{$\begin{array}{l}\text { Anti-torque. } \\
{[\mathrm{Nm}]}\end{array}$} & \multicolumn{2}{|c|}{$\begin{array}{l}\text { Temper. } \\
{\left[{ }^{\circ} \mathbf{C}\right]} \\
\end{array}$} & \multirow[t]{2}{*}{ Comments/ Leakage } \\
\hline & & & & initial & final & initial & final & \\
\hline $\mathrm{C} 1$ & 4000 & 10.47 & 2.30 & 0.128 & 0.500 & 23 & 78 & $\begin{array}{l}\text { Replacement of MF. Sudden increase of temperature } \\
\text { and anti-torque / No leakage }\end{array}$ \\
\hline $\mathrm{C} 2$ & 4000 & 10.47 & 1.70 & 0.140 & 0.500 & 23 & 70 & $\begin{array}{c}\text { No replacement of MF. Sudden increase } \\
\text { of temperature and anti-torque / No leakage }\end{array}$ \\
\hline $\mathrm{C} 3$ & 4200 & 11.00 & 0.80 & 0.150 & 0.220 & 23 & 70 & $\begin{array}{l}\text { No replacement of MF. Sudden increase } \\
\text { of temperature and anti-torque / No leakage }\end{array}$ \\
\hline $\mathrm{C} 4$ & 3000 & 7.85 & 2.00 & 0.230 & 0.150 & 21 & 72 & Replacement of MF/ No leakage. \\
\hline $\mathrm{C} 5$ & 4800 & 12.57 & 0.45 & 0.190 & 0.501 & 23 & 71 & $\begin{array}{l}\text { No replacement of MF. Changeable anti-torque; } \\
\text { its sudden increase within the last min./ No leakage }\end{array}$ \\
\hline C6 & 5400 & 14.14 & 0.50 & 0.175 & 0.320 & 27 & 75 & $\begin{array}{l}\text { No replacement of MF. Stable anti-torque; } \\
\text { its sudden increase within the last } 30 \mathrm{sec} / \\
\text { Total leakage : } 5 \text { drops. }\end{array}$ \\
\hline $\mathrm{C} 7$ & 6000 & 15.71 & 0.07 & 0.180 & 0.150 & 23 & 28 & $\begin{array}{c}\text { No replacement of MF / } \\
\text { Dropping leakage evolving to continuous flow. }\end{array}$ \\
\hline $\mathrm{C} 8$ & 4200 & 11.00 & 1.00 & 0.200 & 0.150 & 23 & 60 & Replacement of MF/ No leakage. \\
\hline C9 & 4800 & 12.57 & 3.50 & 0.170 & 0.090 & 22 & 75 & $\begin{array}{l}\text { No replacement of MF / Sudden leakage of } 14 \text { drops } \\
\text { within 4-th min.; no leakage up to the end of the test. }\end{array}$ \\
\hline $\mathrm{C} 10$ & 5400 & 14.14 & 1.17 & 0.150 & 0.077 & 23 & 73 & $\begin{array}{c}\text { No replacement of MF / After one minute - a leakage } \\
\text { increasing to } 11 \text { drops per minute } \\
\text { at the end of the test. }\end{array}$ \\
\hline
\end{tabular}


the seal of $\mathrm{C}$ version fitted with the additional protecting set of sealing rings, was continuously increasing, and that of the seal of $\mathrm{B}$ version without any protecting elements, became stable on the level of $52^{\circ} \mathrm{C}$.

\section{FINAL REMARKS}

The presented results of the tests of the seal of $50 \mathrm{~mm}$ diameter at $3000 \mathrm{rpm}$ rotational speed show that MF seal can effectively work for a long time in water, at geometrical and operational parameters usually met in industrial devices.

Loss of tightness of MF seal working in liquid occurs after exceeding a determined value of seal's rotational speed at which the sealed fluid starts penetrating through the sealing magnetic fluid. The performed tests indicate that the process of loss of tightness can be reversible. A decrease of rotational speed makes tightness of the system recovered.

- Application of a simple set of rings protecting MF seal resulted in the distinct increase (by about $1000 \mathrm{rpm}$ ) of the speed at which leakage occurred. It shows that it is possible to increase limiting values of geometrical and operational parameters of MF seals working in water by applying appropriate design solutions.

However attention should be paid to the fact that in all the tests the application of the protecting set of sealing rings resulted in fast increase of seal's temperature. As the correct work temperature of magnetic fluids is limited to about $100^{\circ} \mathrm{C}$ a research to disclose causes of the phenomenon and its consequences should be undertaken.

\section{NOMENCLATURE}

MF - Magnetic Fluid Seals

FF - Ferro Fluidic Seals

\section{BIBLIOGRAPHY}

1. B. M. Berkovsky: Magnetic fluids engineering applications, Oxford University Press, Oxford-New York-Tokyo,1993.

2. Z. Szydło, W. Ochoński, B. Zachara: Experiments on magnetic fluid rotary seals operating under vacuum conditions, Tribotest Journal, 2005 vol. 11 no. 4.

J. Kurfess, H.K. Müller: Sealing Liquids with Magnetic Fluids, Journal of Magnetism and Magnetic Materials 85, 1990.

3. Z. Szydło, L. Matuszewski: Ring driving unit-preliminary investigations on optimization of ferro-fluidal seals and drives (in Polish).

4. W. Ochoński, Z. Szydlo, B. Zachara: Experimental study of frictional characteristics of magnetic fluid shaft seals, Proc. Int. Tribology Conf., Nagasaki, Japan (2000)

\section{CONTACT WITH THE AUTHORS}

Leszek Matuszewski, Ph. D.

Faculty of Ocean Engineering and Ship Technology

Gdansk University of Technology

Narutowicza 11/12

80-952 Gdansk, POLAND

e-mail : leszekma@pg.gda.pl

Zbigniew Szydło, Ph. D.

AGH University of Science and Technology

Al. Mickiewicza 30

30-059 Kraków, POLAND

e-mail : zszydlo@uci.agh.edu.pl

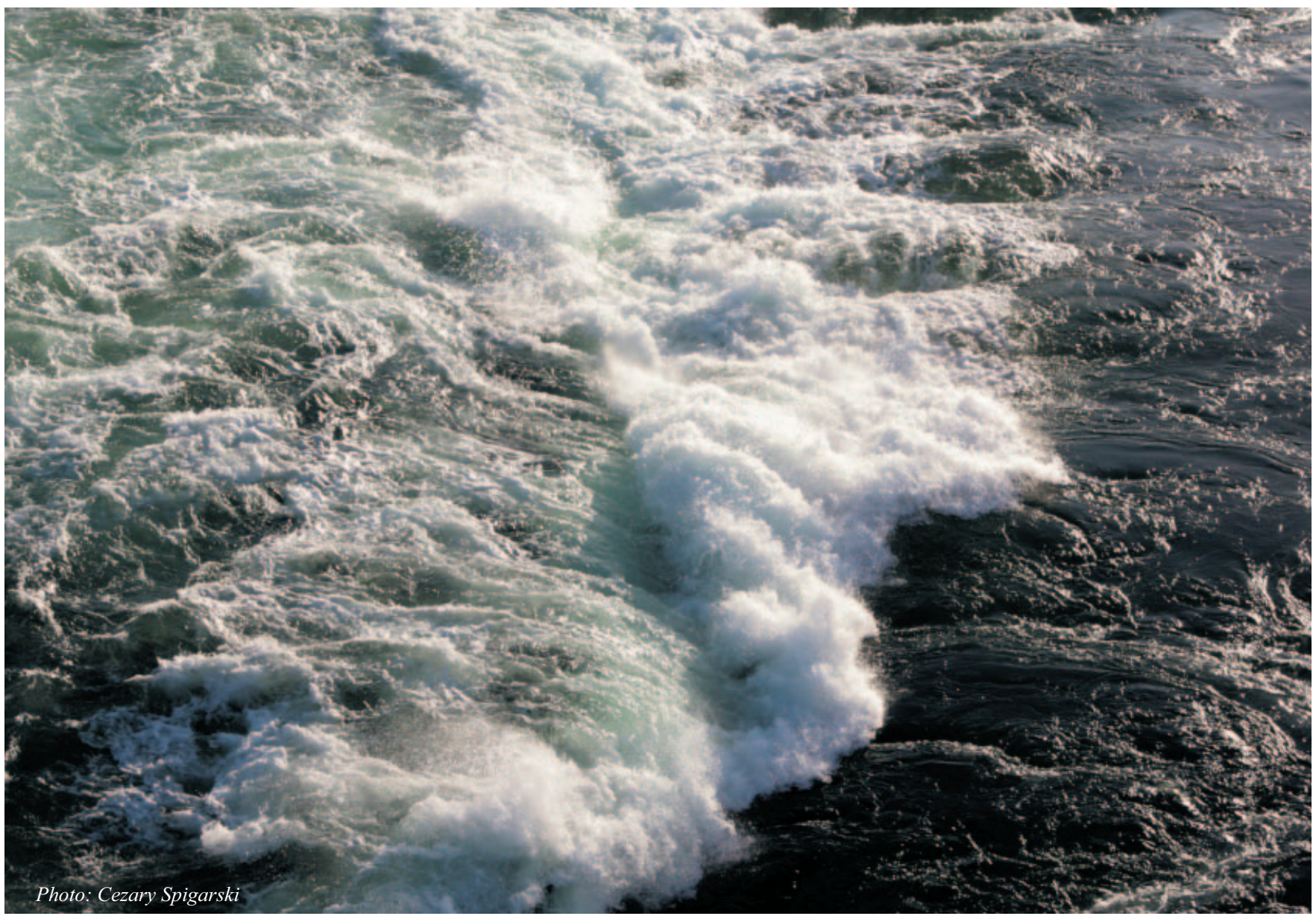

